\title{
Fabrication and formation mechanism of poly(L-lactic acid) ultrafine multi-porous hollow fiber by electrospinning
}

\author{
Q. Z. Yu* ${ }^{*}$ Y.M. Qin \\ College of Materials and Textile Engineering, Zhejiang Materials and Light Chemical and Textile Engineering \\ Experiment Center, Jiaxing University, 314001 Jiaxing Zhejiang, P. R. China
}

Received 16 June 2012; accepted in revised form 22 August 2012

\begin{abstract}
Poly(L-lactic acid) (PLLA) ultrafine multi-porous hollow fibers are fabricated by electrospinning with methylene dichloride as solvent. The Kirkendall effect has been widely applied for the fabrication of hollow structure in metals and inorganic materials. In this study, a conceptual extension is proposed for the formation mechanism: the development of porous hollow fiber undergoes three stages. The initial stage is the generation of small voids or pits on the surface of the fiber via surface diffusion and phase separation; the second stage is the formation of multi-pores penetrating the core of the fiber through the interaction of Kirkendall effect, surface diffusion and phase separation; the third stage is dominated by surface diffusion of the core material along the pore surface. To explore the formation conditions, the factors including ambient temperature, relativity humidity (R. H.), molecular weight and fiber diameter are studied. The longitudinal and cross sectional morphologies of these fibers are examined by scanning electron micrograph (SEM). The results show that the prerequisite for the formation of uniform porous hollow PLLA fibers include moderate ambient temperature $\left(10 \sim 20^{\circ} \mathrm{C}\right)$ and appropriate molecular weight for the PLLA, as well as the diameter of the fiber in the range of several micrometers to about 100 nanometers.
\end{abstract}

Keywords: biodegradable polymers, electrospinning, multi-porous hollow fiber, microstructure, mechanism

\section{Introduction}

Many of the applications of electrospun fibers could be greatly enhanced by increasing the surface area and porosity of the fibers. To this purpose, reliable production of porous nanofibers in a simple and inexpensive way has been attempted by a number of groups. Previous methods of producing porous polymer fibers relied on either the electrospinning of blends followed by selective removal of one of the phases or phase separation based on the evaporation of solvent or in the presence of vapor.

PLLA nonwoven fibrous matrices have been widely used in various tissue regenerative therapies because of their excellent mechanical properties and biocompatibility [1-3]. Many researchers have engaged in fabricating multi-porous PLLA fiber membrane with various methods. Lee and his coworker [4] fabricated dual-porosity structure PLLA/MMT fibers by combining electrospinning with salt leaching method. Qi et al. [5] fabricated PLLA fibers with micro- and nano-porous structure by electrospinning a ternary system of nonsolvent/solvent/PLLA. It is reported by Zhang et al. [6] when PLLA was dissolved in dimethylformamide (DMF) and methylene chloride $\left(\mathrm{CH}_{2} \mathrm{Cl}_{2}\right)$ mixed solvent with different ratios, semi-hollow fiber with porous inner structure and compact shell wall was formed by controlling the content of DMF in the mixed solvents. But there is little report that the micro- and nano- porous outer structures of PLLA ultrafine hollow fibers were

\footnotetext{
${ }^{*}$ Corresponding author, e-mail: w2003yqz@126.com

(c) BME-PT
} 
fabricated only by electrospinning with only one solvent. Although Bognitzki et al. [7] reported the use of dichloromethane yielded PLLA fibers with a regular pore structure by electrospinning and considered the regular phase morphology is generated by rapid phase separation during the electrospinning process. There has been no report about the fabrication of PLLA ultrafine hollow fibers with multi-porous outer structure by electrospinning and detailed analysis about the formation mechanism of this structure.

The Kirkendall effect is a classical phenomenon in metallurgy [8-9]. It basically refers to a non-equilibrium mutual diffusion process through an interface of two metals so that vacancy diffusion occurs to compensate for the unequal material flow. Atomic diffusion occurs through vacancy exchange and not by the direct interchange of atoms. The net directional flow of matter is balanced by an opposite flow of vacancies, which can condense into pores or annihilate at dislocations. In a spherical material system where the fast-diffusion phase is enclosed by the slower one, the Kirkendall effect can also apply and manifest itself by forming hollow crystals composed of a compound shell. Coming to the nanoscale, due to the structural perfection and wide availability of single crystal metal nanoparticles, the Kirkendall effect can result in smooth and uniform-sized hollow compound nanocrystals [10-12]. An extension to cylindrical nanotubes has recently been reported via either a solid - solution, solid gas, or solid - solid reaction [13-16].

In this paper, PLLA ultrafine hollow fibers with multi-porous outer structure were prepared only by electrospinning with only one solvent. The exact growth mechanism for the formation of this structure is still under investigation, but on the basis of experimental observations, a mechanism based on the 'Kirkendall effect + surface diffusion' model [8] was proposed.

\section{Experimental section}

\subsection{Materials}

PLLA ( $\left.M_{\mathrm{W}}: 100000 \sim 70000, M_{\mathrm{w}} / M_{\mathrm{n}}: 1.40\right)$ chips were purchased from Jiaxing Haobang Science and Technology Development Co., Jiaxing, China. Methylene dichloride, A. R, was supplied from Guoyao Chemical Company, Shanghai, China. Hxafluoroisopropanol (HFIP), A. R, was purchased from
Huaweiruike Chemical Limited.Company, Beijing, China. Pyrrole monomer was distilled under reduced pressure and stored below $0^{\circ} \mathrm{C}$. All the other reagents were analytical grade, and were used without further purification.

\subsection{Preparation}

\subsubsection{Preparation of PLLA fibers}

10 or $12 \mathrm{wt} \%$ PLLA in methylene dichloride or HFIP was prepared by dissolving PLLA chips in methylene dichloride or HFIP under magnetic stirring for at least $5 \mathrm{hrs}$, the solution was held in a syringe for electrospinning. A voltage of $12 \mathrm{kV}$ was applied to the solution and the fibers were collected on the flat aluminum plate. The distance from the tip of the nozzle to the collector was $15 \mathrm{~cm}$.

\subsubsection{Preparation of PLLA/polypyrrole(PPy) composite fibers}

PPy was introduced by the in situ polymerization on the surface of the obtained PLLA fibers mentioned above section. Typically, $0.25 \mathrm{~g}$ of pyrrole was dissolved in $20 \mathrm{~mL}$ of $1 \mathrm{M} \mathrm{H}_{2} \mathrm{SO}_{4}$ solution with stirring. Some PLLA fibers with a length of $200 \mathrm{~mm}$ immersed into the above solution followed by ultrasonication for $30 \mathrm{~min}$ to allow the fibers to be saturated with the pyrrole solution. $0.61 \mathrm{~g}$ of ammonium persulfate (APS) in $20 \mathrm{~mL}$ of $1 \mathrm{M} \mathrm{H}_{2} \mathrm{SO}_{4}$ solution was added dropwise to the above mixture with the ultrasonic aided dispersing. Then the polymerization proceeded for $5 \mathrm{~h}$ without any dispersing. The fibers were then washed 3 times with $40 \mathrm{~mL}$ of deionized water and acetone in sequence. Finally, the fibers were dried under vacuum and stored for usage.

\subsection{Characterization}

The morphologies of electrospun PLLA fibers fabricated under different conditions were observed using Hitachi JSM-5510 SEM. The specimen used for imaging the cross-section of the electrospun fiber was prepared by dropping a drop of collodion on the sample, followed by cutting with a sharp knife.

\section{Results and discussion}

Fixing the PLLA weight percent [wt $\%]$ in methylene dichloride at $12 \mathrm{wt} \%$, the SEM images of fibers fabricated at $15^{\circ} \mathrm{C}$ and different R. H. are shown in 


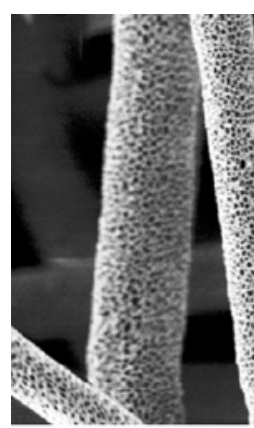

a)
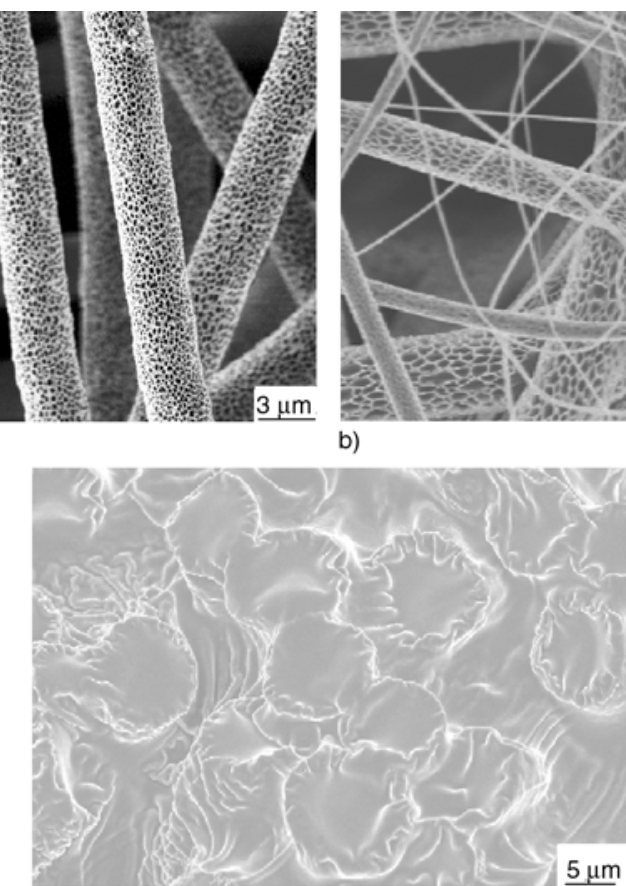

d)

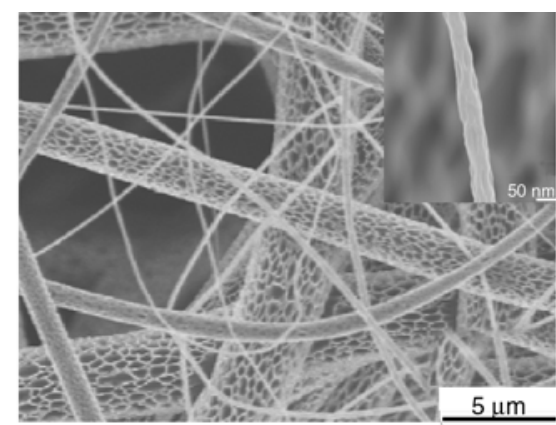

b)

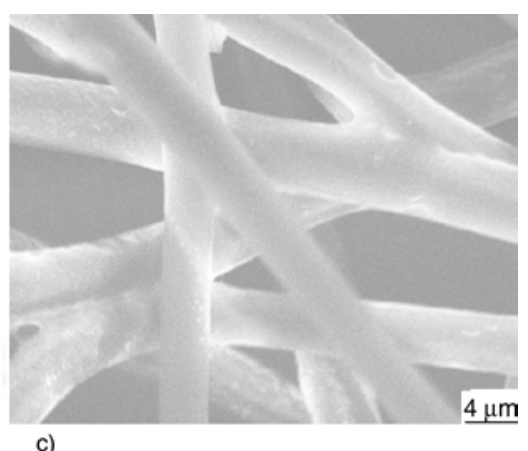

c)

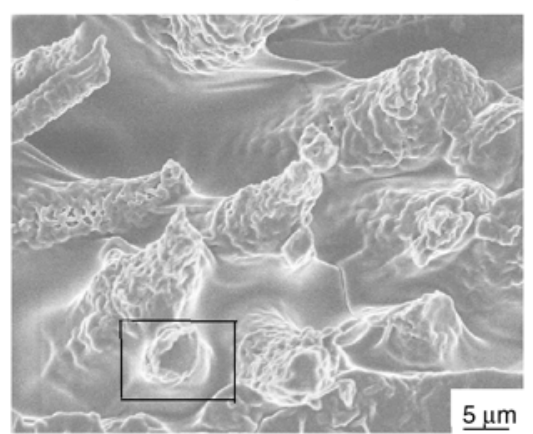

e)

Figure 1. SEM images of the fibers fabricated at $15^{\circ} \mathrm{C}$ and different R. H. (a) $28 \%$, with higher molecular weight $\left(M_{\mathrm{W}}\right.$ : $\left.100000, M_{\mathrm{W}} / M_{\mathrm{n}}: 1.40\right)$ PLLA; (b) 49\%, the inset is the corresponding higher-magnification image of a nanofiber, with higher molecular weight $\left(M_{\mathrm{W}}: 100000, M_{\mathrm{W}} / M_{\mathrm{n}}: 1.40\right)$ PLLA; (c) 49\%, with lower molecular weight $\left(M_{\mathrm{W}}\right.$ : $\left.70000, M_{\mathrm{W}} / M_{\mathrm{n}}: 1.40\right)$ PLLA; (d) cross section of (a); (e) cross section of (b).

Figure 1. Figure 1a-1c is the longitudinal morphologies of these fibers and Figure 1d-1e is the corresponding cross-sectional one. From Figure 1, it can be found that most fibers are multi-porous fibers with diameters ranging from 3 to $7.2 \mu \mathrm{m}$, but the fibers fabricated at $15^{\circ} \mathrm{C}, 28 \% \mathrm{R}$. H. are more uniform in diameter and pore size than those fabricated at $15^{\circ} \mathrm{C}, 49 \% \mathrm{R}$. H. The most interesting thing is that, from Figure 1d-1e, we noticed that some fibers with diameters range from 3 to $7.2 \mu \mathrm{m}$ not only have multi-porous outer structure, but also have visible holes in the inner region of the fibers. That is, these fibers are hollow fibers with multi-porous outer structure; although the holes of some fibers are closed because of becoming too soft to maintain the shape when they were cut and at the action of the solidification of collodion.

To further confirm the hollow structure, these PLLA fibers were used as matrix to fabricate PLLA/PPy composite fibers by in situ polymerization. The obtained PLLA/PPy composite fibers have obvious core-shell structure and smooth fractured surface of the core, as shown in Figure 2 [17]. This fact demonstrates these PLLA fibers are really hollow fibers.

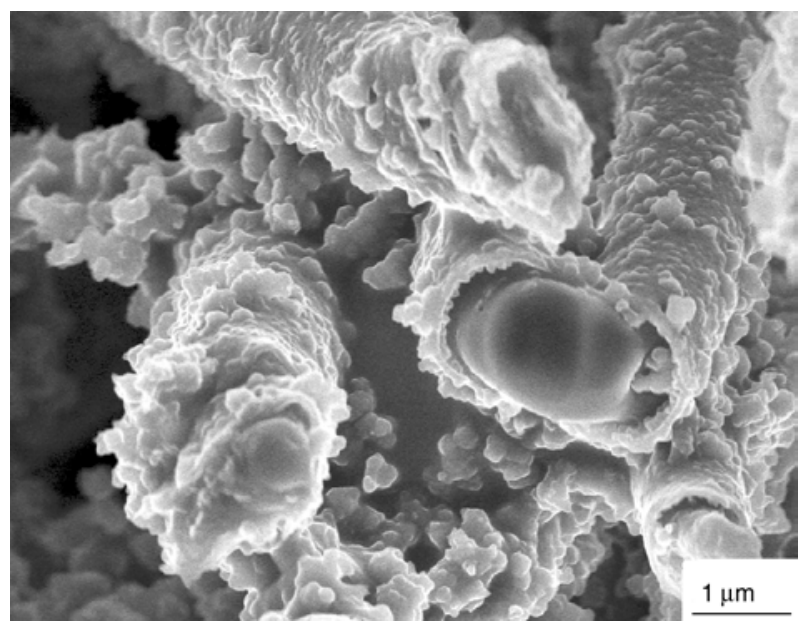

Figure 2. SEM image of the cross section of PLLA/PPy micro fibers [17]

Some reports [7] considered the formation of pores or pits in the electrospinning fibers controlled by a rapid phase separation induced by the evaporation of the solvent and a subsequent rapid solidification. The exact mechanism of porous hollow fiber fabricated by electrospinning with only one solvent is not fully understood. Here, we propose a formation mechanism based on the void formation in 'Kirk- 


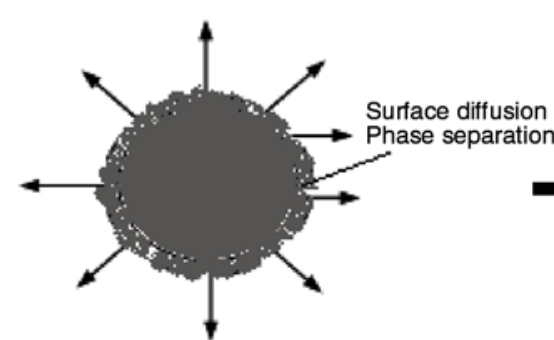

a)

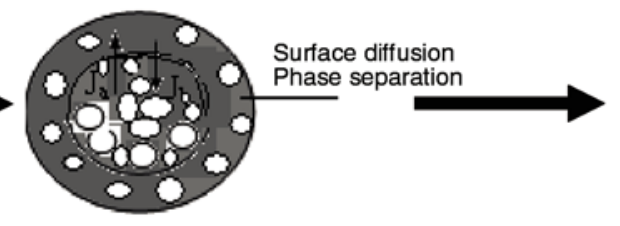

b)

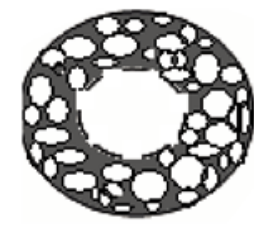

c)

Figure 3. Simplified schematic representation of the formation of porous hollow structure (cross section) (a) the initial stage, (b) the second stage, (c) the third stage

endall effect + surface diffusion' model [16]. Figure 3 shows schematically this generalized model. In the initial stage (Figure 3a), due to the rapid volatilization of the methylene dichloride through surface diffusion result in the dropping of the surface temperature, the phase separation occur and form the voids or pits on the surface of the fiber [16]. In the second stage (Figure 3b), driven by concentration gradient, the methylene dichloride molecules diffuse outward continuously and the PLLA molecular chains condense inward. The mutual diffusion rates of the methylene dichloride and PLLA molecular differ by a considerable amount. For the diffusion flux, $J_{\mathrm{a}}>J_{\mathrm{b}}$ ( $a$ index methylene dichloride and $b$ index PLLA). A large quantity of vacancies diffusion occur to compensate for the unequal material flow between methylene dichloride molecules and PLLA molecular chains, the voids are enclosed by the slower PLLA molecular chains. In a sub-micro system, due to the finite volume and spatial confinement, a high vacancy supersaturation can readily be reached [10]. Thus, the voids have a high chance to touch the outer layer of the fiber, resulting in the multi-pores penetrating the core of the fiber. The voids coalesce into bigger ones and touch the compound layer $\mathrm{ab}$, on one hand breaking the connection between PLLA molecular chains and on the other hand establishing new bridges as fast transport paths for the methylene dichloride molecules. At this stage (Figure 3c), diffusion of molecules of the remaining methylene dichloride along the bridges, i.e. the pore surface, to the reaction front becomes the dominant material transport process. The methylene dichloride can redistribute itself at the open surface of the methylene dichloride and PLLA mixture via fast surface diffusion. While within the methylene dichloride and PLLA mixture, the material exchange mechanism remains the
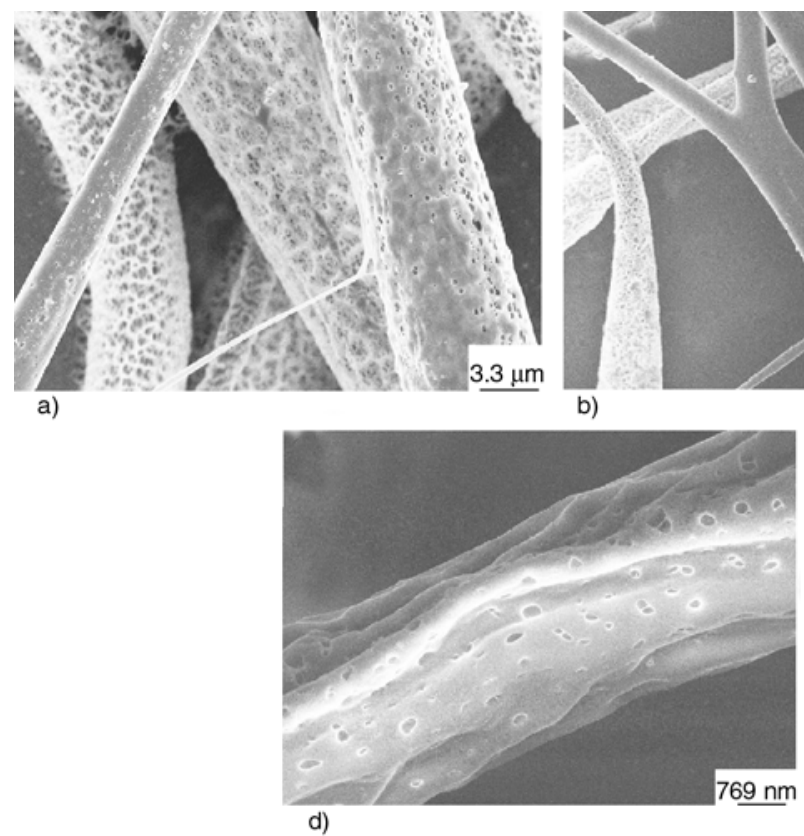

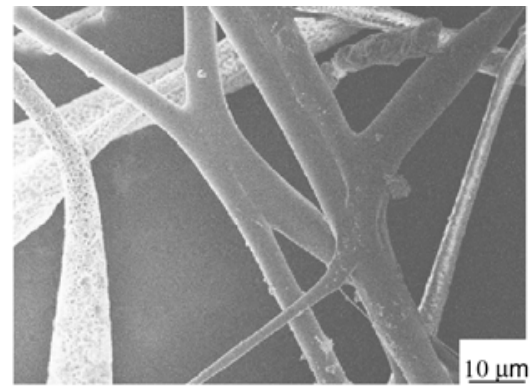

b)

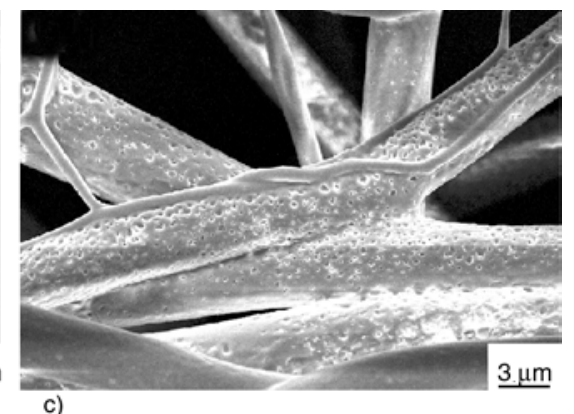

c)

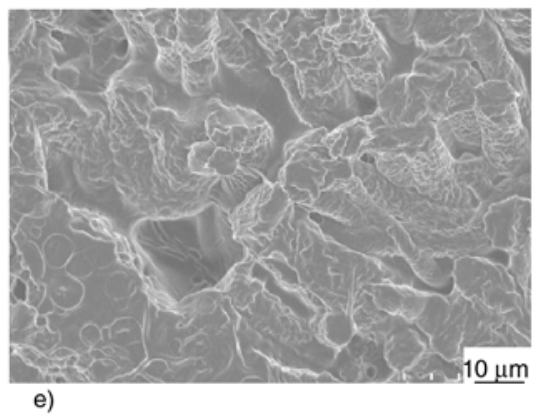

Figure 4. SEM images of the fibers fabricated at (a) and (b) $26^{\circ} \mathrm{C}, 50 \% \mathrm{R}$. H.; (c) and (d) $26^{\circ} \mathrm{C}, 80 \% \mathrm{R}$. H.; (e) cross section of (a). PLLA weight percent in methylene dichloride was $12 \mathrm{wt} \%$. 


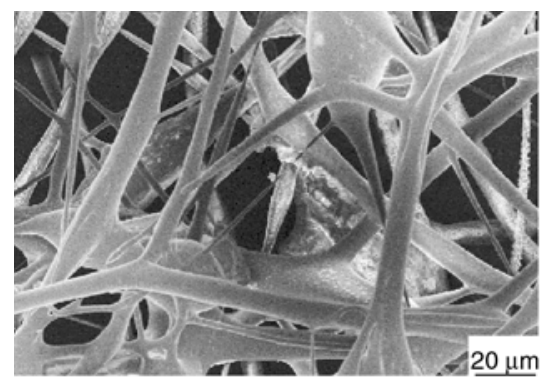

a)

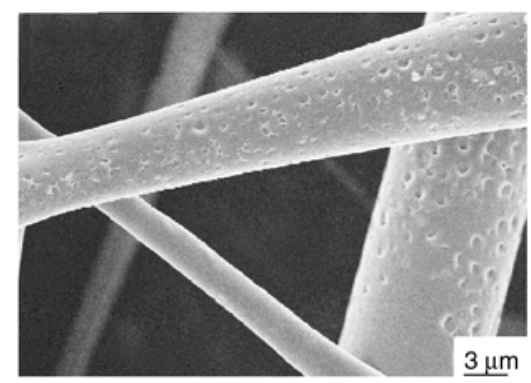

b)

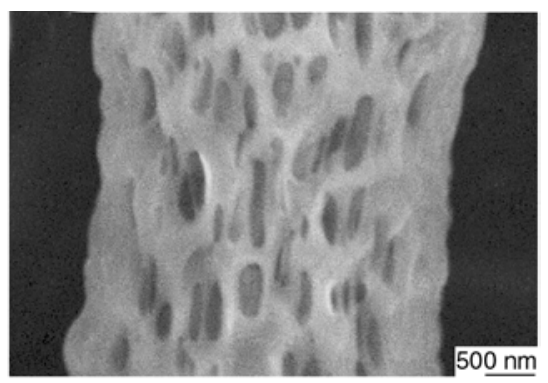

c)

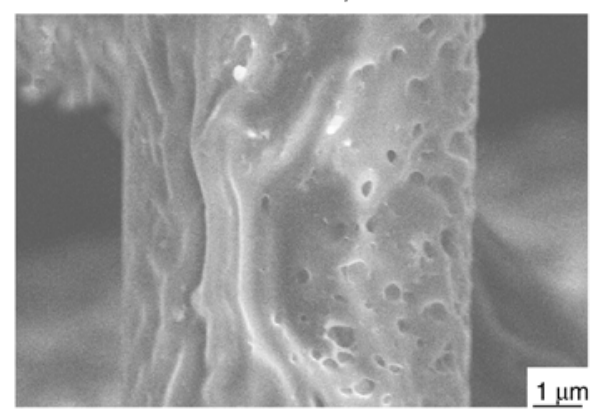

d)

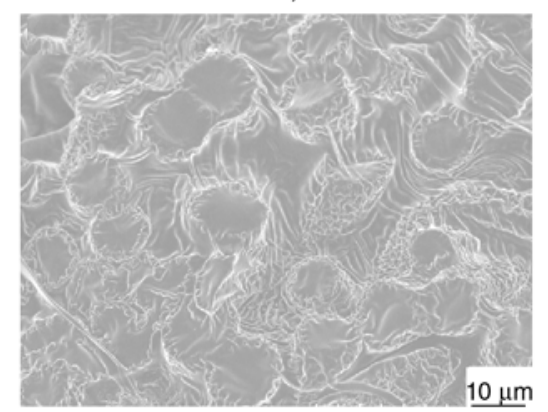

e)

Figure 5. (a) SEM images of the fibers fabricated at $34^{\circ} \mathrm{C}, 60 \%$ R. H. (b), (c) and (d) the corresponding high magnification of (a) in different sections; (e) cross section of (a). PLLA weight percent in methylene dichloride at $12 \mathrm{wt} \%$.

same, viz. bulk interdiffusion associated with Kirkendall effect. Therefore vacancies are continuously generated and flow inward. The hollow multi-porous fiber is formed.

To further explore the formation conditions, we fabricated some fibers above $20^{\circ} \mathrm{C}$. When the ambient temperature was above $20^{\circ} \mathrm{C}$, the obtained fibers with diameters of several micrometers are not uniform in both the morphologies and diameters, as shown in Figures 4-5. Some sections of the fibers only have some pits on the surface; while some sections have no visible pores. Moreover, the pore size and distribution of the pores in the sections with multi-pores are also not uniform; while some sections also have multi-pores penetrating the core of the fiber (Figures 4a, 4e and Figures 4c-4e).

These indicate that under too high ambient temperature (above $20^{\circ} \mathrm{C}$ ), the electrospinning jet is unstable due to the rapid volatilization of the solvent through surface diffusion. It can be confirmed by observing the shapes of the jets.

Appropriate ambient temperature is the prerequisite to fabricate uniform porous hollow PLLA fibers by electrospinning. As we know, the boiling temperature of methylene dichloride is $39.8^{\circ} \mathrm{C}$. The closer the ambient temperature to the methylene dichloride boiling temperature is, the higher its volatilization rate is.
In addition, the collapsed wrinkled skins are also found on some sections of the fibers (Figure $4 \mathrm{~d}$ and Figure 5d). One of the explanations is that at high ambient temperature, especially when it is near its boiling temperature, the solvent evaporation rate is very high through fast surface diffusion, and this might induce the formation of fibers with sheathcore structure due to the different solidification speed between the outer layer and the inner layer. The further solidification and shrinkage of the core would result in local collapse of outer layer [18, 19]. The surface diffusion and phase separation resulted in pits on the surface of nanofibers with a diameter smaller than about $50 \mathrm{~nm}$, as shown in the inset of Figure $1 \mathrm{~b}$. Surface diffusion becomes the dominant solvent transport process due to the very higher surface area in the nanofibers. The rapid evaporation of methylene dichloride on the surface of the fibers and fast solidification induce the formation of fibers with sheath-core structure. The further solidification and shrinkage of the core result in pits occurred on the surface of the fibers. If the fibers with a diameter larger than several micrometers, due to the large space, a high vacancy supersaturation will be difficult to reached. Thus, the voids have a low chance to touch the outer layer of the fiber, resulting in some pits not penetrating the core of the fiber. 


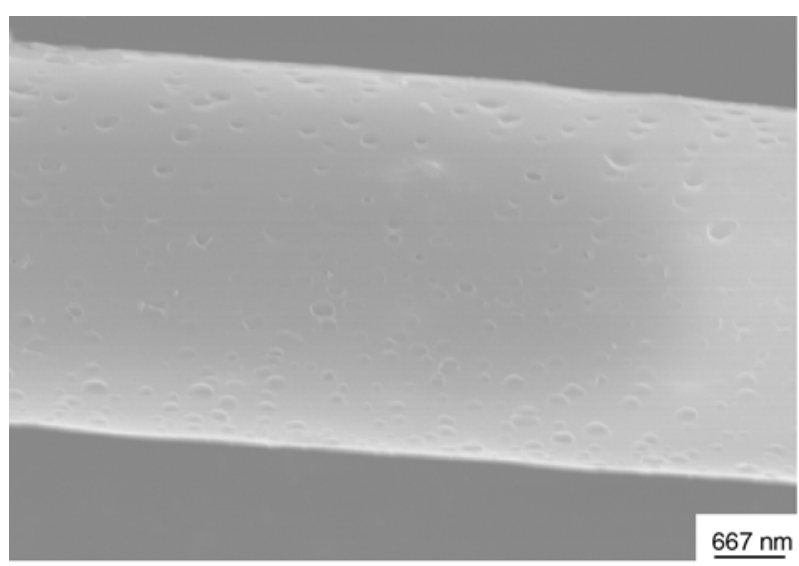

a)

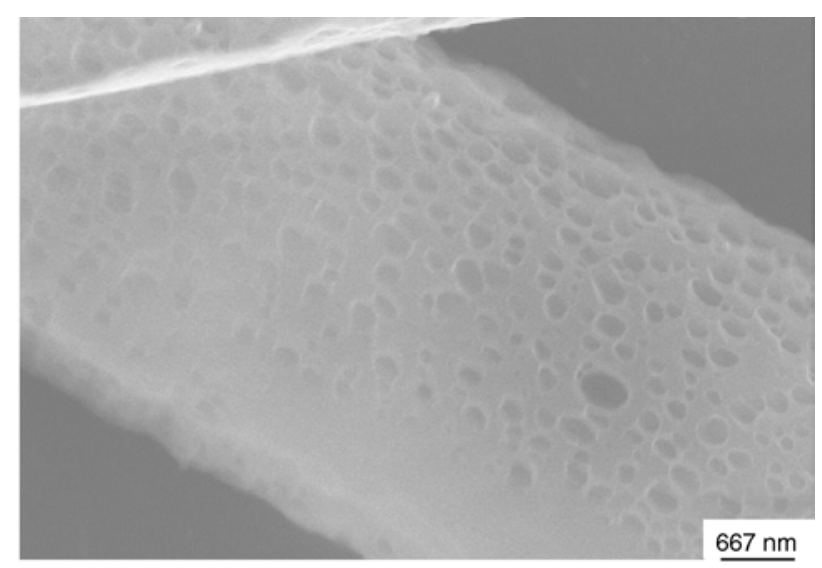

b)

Figure 6. SEM images of the fibers fabricated at $8^{\circ} \mathrm{C}, 45 \% \mathrm{R}$. H. with different PLLA concentrations (a) $10 \mathrm{wt} \%$; (b) $8 \mathrm{wt} \%$, PLLA $M_{\mathrm{W}}$ was 100000 and $M_{\mathrm{W}} / M_{\mathrm{n}}$ was 1.40

As weight percent of PLLA is fixed at $12 \mathrm{wt} \%$, using the lower molecular weight $\operatorname{PLLA}\left(M_{\mathrm{W}}: 70000\right.$, $\left.M_{\mathrm{W}} / M_{\mathrm{n}}: 1.40\right)$ to elecrospin the PLLA fibers, the obtained fibers only have pits on their surface, as shown in Figure 1c. The low molecular weight PLLA has high molar percent of polymer molecular, which upon methylene dichloride evaporation contributes to retain less methylene dichloride to form porous surface [20]. In addition, the low molecular weight PLLA has more molecules with relatively lower molecular weight and shorter molecular chains, the diffuse rate of these PLLA molecules are higher than those PLLA molecules with higher molecular weight, and result in less quantity of vacancies diffusion resulting from Kirkendall effect occur to compensate for the unequal material flow between methylene dichloride molecules and PLLA molecular chain. Thus, it will become difficult to reach a high vacancy supersaturation and reduce the chance of voids to touch the outer layer of the fiber, resulting in some pits not penetrating the core of the fiber.

We also observed the PLLA fibers fabricated by electrospinning at $8^{\circ} \mathrm{C}$ have only pits on the surface, as shown in Figure 6. Moreover, the pits enlarged with the PLLA concentration decreased. This is because of the low temperature result in slow evaporation rate and diffusion rate of methylene dichloride, forming fewer vacancies and low gas pressure within the fibers. Thus it is difficult to form enough large pores.

This can be confirmed by using HFIP, which has lower volatilization rate than that of $\mathrm{CH}_{2} \mathrm{Cl}_{2}$ at the same ambient temperature, as the solvent for PLLA solution. Figures $7 \mathrm{a}, 7 \mathrm{c}, 7 \mathrm{e}$ and Figures $7 \mathrm{~b}, 7 \mathrm{~d}, 7 \mathrm{f}$ are the SEM images of the samples fabricated by using $\mathrm{CH}_{2} \mathrm{Cl}_{2}$ or HFIP as solvent, respectively. It can be seen that the obtained fibers all have beads due to the low viscosity, but it can be obviously seen that the fibers fabricated by using $\mathrm{CH}_{2} \mathrm{Cl}_{2}$ as solvent are multi-porous fibers while the fibers fabricated by using HFIP as solvent are not (Figure 7f), only some pits can be found even in the bigger beads (Figure 7d).

\section{Conclusions}

PLLA hollow fiber with multi-porous outer structure can be fabricated by electrospinning with only one solvent. But it must be fabricated at moderate ambient temperature $\left(10 \sim 20^{\circ} \mathrm{C}\right)$, using appropriate molecular weight $\left(M_{\mathrm{W}}\right.$ : about $100000, M_{\mathrm{W}} / M_{\mathrm{n}}$ : about 1.40) PLLA to electrospin and has a diameter in the range of several micrometers to 100 nanometers.

The formation of multi-porous hollow fiber is a complex process. We propose a formation mechanism of the result of mutual action of 'Kirkendall effect, surface diffusion and phase separation'.

We believe the technique described here can be extended to many other materials for the fabrication of such kind of fibrous scaffolds with potential applications not only in tissue engineering, but also in catalysis, sensing, encapsulation, drug delivery and filtration. 


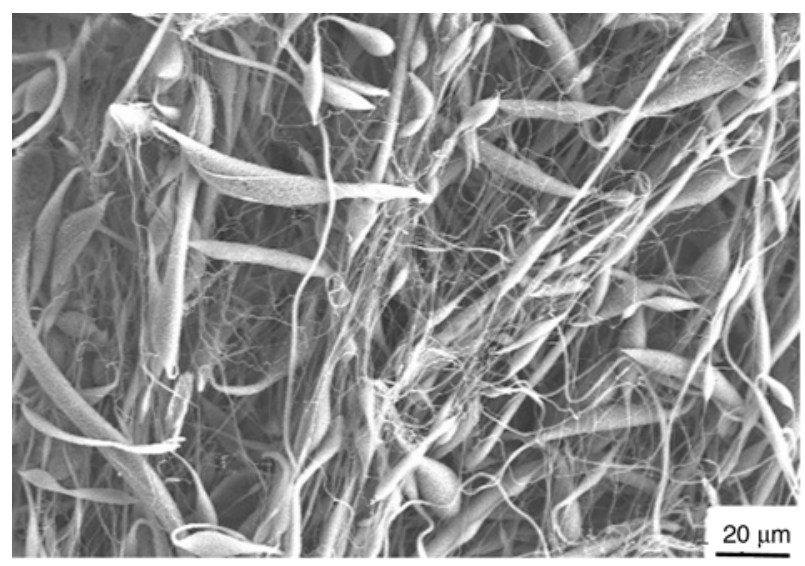

a)

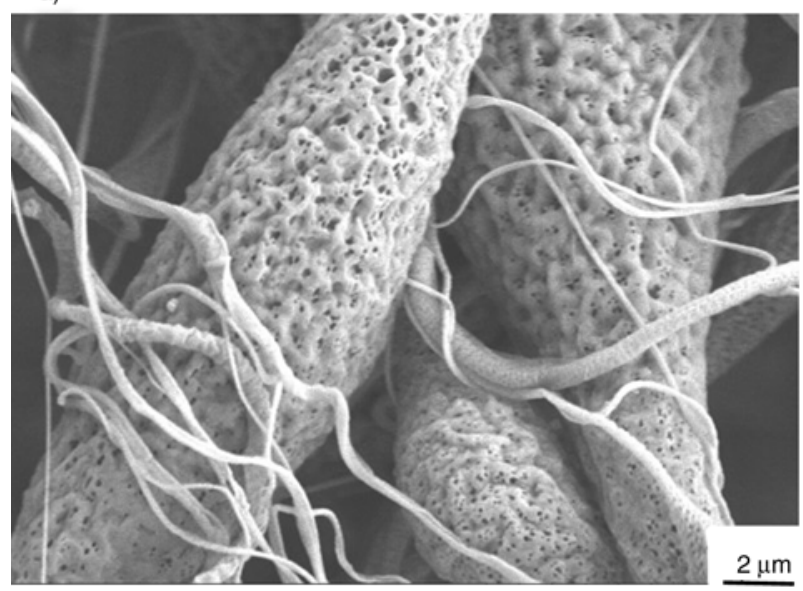

c)

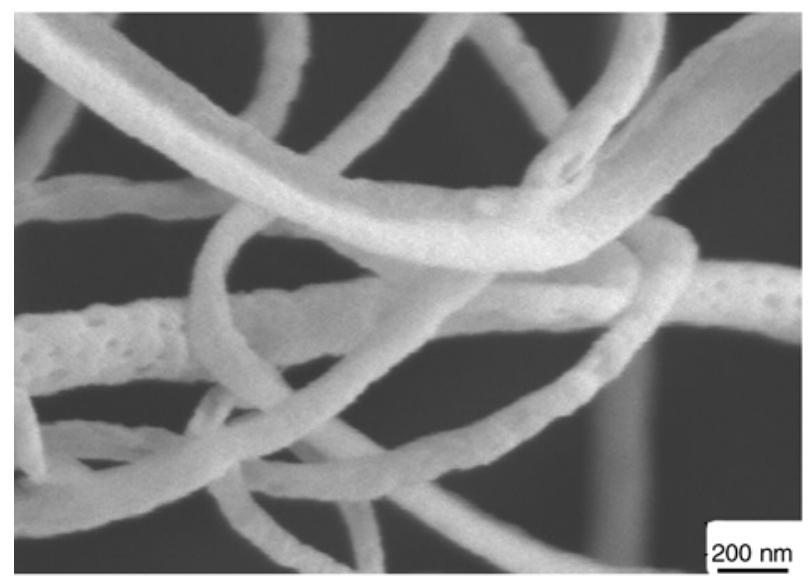

e)

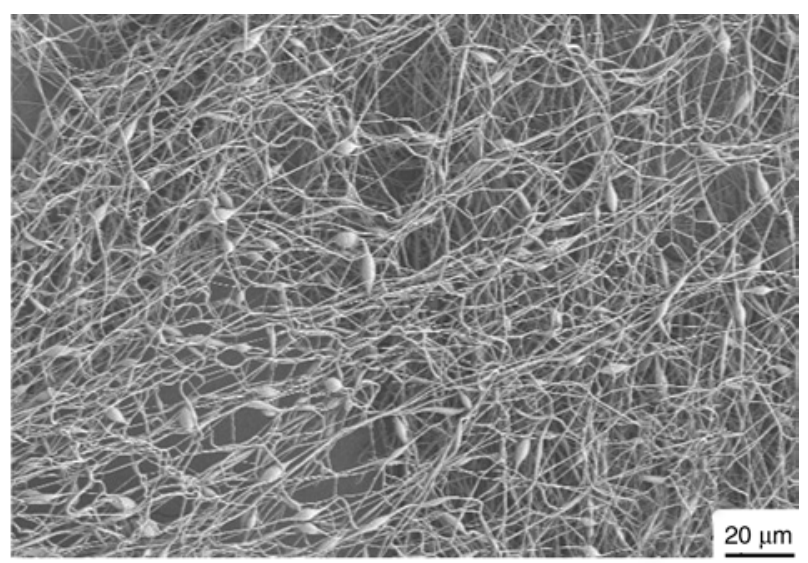

b)

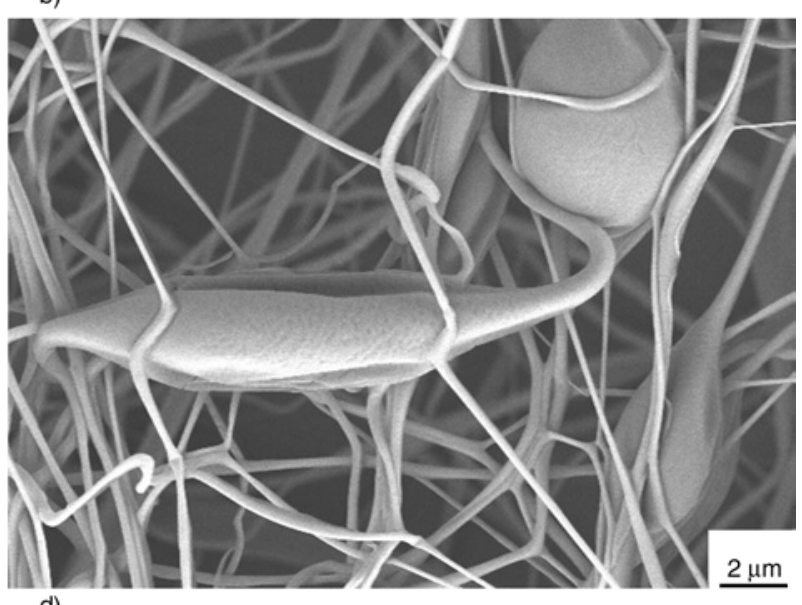

d)

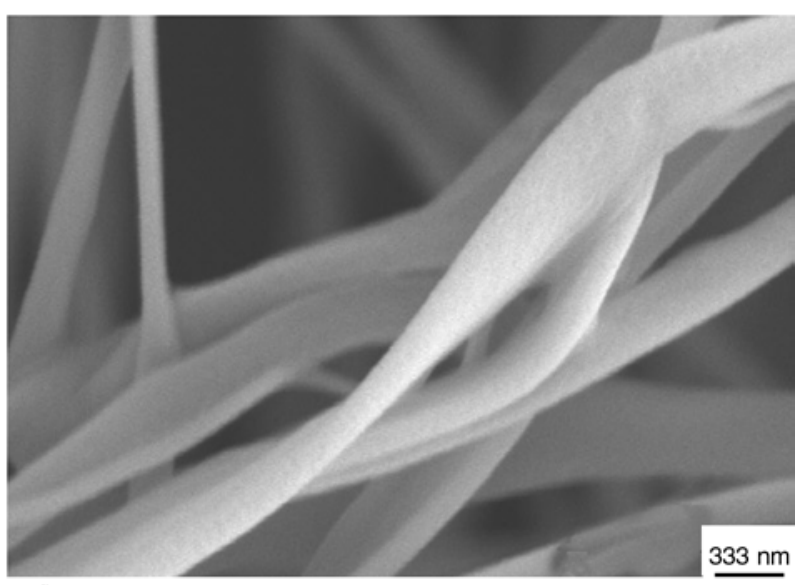

f)

Figure 7. SEM images of the fibers fabricated by different solvent (a) $\mathrm{CH}_{2} \mathrm{Cl}_{2}$, (c) and (e) the corresponding high magnification of (a) in different sections; (b) HFIP, (d) and (f) the corresponding high magnification of (b) in different sections. The ambient temperature was $28^{\circ} \mathrm{C}$, and R. H. was $25 \%$. PLLA weight percent in solvent was $10 \mathrm{wt} \%$. PLLA $M_{\mathrm{W}}$ was 100000 and $M_{\mathrm{W}} / M_{\mathrm{n}}$ was 1.40 .

\section{Acknowledgements}

This work was supported by the National Natural Science Foundation of China (No. 51073072), the Zhejiang Provincial Natural Science Foundation of China (No. Y4100745), the Key Laboratory Open Foundation of Advanced Textile Materials \& Manufacturing Technology of Zhejiang SciTech University from Ministry of Education of China (No. 2009007)

\section{References}

[1] Scaffaro R., Morreale M., Mirabella F., La Mantia F. P.: Preparation and recycling of plasticized PLA. Macromolecular Materials and Engineering, 296, 141-150 (2011).

DOI: $\underline{10.1002 / m a m e .201000221 ~}$ 
[2] Rajeswari R., Sundarrajan S., Venugopal J. R., Mukherjee S., Ramakrishna S.: Advances in polymeric systems for tissue engineering and biomedical applications. Macromolecular Bioscience, 12, 286-311 (2012). DOI: 10.1002/mabi.201100325

[3] Naveena N., Venugopal J., Rajeswari R., Sundarrajan S., Sridhar R., Shayanti M., Narayanan S., Ramakrishna S.: Biomimetic composites and stem cells interaction for bone and cartilage tissue regeneration. Journal of Materials Chemistry, 22, 5239-5253 (2012).

DOI: $10.1039 / \mathrm{C} 1 \mathrm{JM} 14401 \mathrm{D}$

[4] Lee Y. H., Lee J. H., An I-G., Kim C., Lee D. S., Lee Y. K., Nam J-D.: Electrospun dual-porosity structure and biodegradation morphology of Montmorillonite reinforced PLLA nanocomposite scaffolds. Biomaterials, 26, 3165-3172 (2005).

DOI: $10.1016 /$ j.biomaterials.2004.08.018

[5] Qi Z., Yu H., Chen Y., Zhu M.: Highly porous fibers prepared by electrospinning a ternary system of nonsolvent/solvent/poly(L-lactic acid). Materials Letters, 63, 415-418 (2009).

DOI: $10.1016 /$ j.matlet.2008.10.059

[6] Zhang K., Wang X., Jing D., Yang Y., Zhu M.: Bionic electrospun ultrafine fibrous poly(L-lactic acid) scaffolds with a multi-scale structure. Biomedical Materials, 4, 035004/1-035004/7 (2009).

DOI: $10.1088 / 1748-6041 / 4 / 3 / 035004$

[7] Bognitzki M., Czado W., Frese T., Schaper A., Hellwig M., Steinhart M., Greiner A., Wendorff J. H.: Nanostructured fibers via electrospinning. Advanced Materials, 13, 70-79 (2001).

DOI: 10.1002/1521-4095(200101)13:1<70::AID-

$$
\text { ADMA70>3.0.CO;2-H }
$$

[8] Fan H. J., Knez M., Scholz R., Hesse D., Nielsch K., Zacharias M., Gösele U.: Influence of surface diffusion on the formation of hollow nanostructures induced by the Kirkendall effect: The basic concept. Nano Letters, 7, 993-997 (2007). DOI: $10.1021 / \mathrm{n} 1070026 \mathrm{p}$

[9] Drechsel H., Brechtmann C., Heinrich W., Dreute J., Benton E. V.: Search for anomalous fragments produced in collisions with heavy target nuclei and in $\Delta \mathrm{Z}=1$ peripheral interactions. Physical Review Letters, 54, 1258-1261 (1985). DOI: 10.1103/PhysRevLett.55.1258

[10] Yin Y., Rioux R. M., Erdonmez C. K., Hughes S., Somorjai G. A., Alvisatos A. P.: Formation of hollow nanocrystals through the nanoscale Kirkendall effect. Science, 304, 711-714 (2004).

DOI: $\underline{10.1126 / \text { science. } 1096566}$
[11] Wang Y., Cai L., Xia Y.: Monodisperse spherical colloids of $\mathrm{Pb}$ and their use as chemical templates to produce hollow particles. Advanced Materials, 17, 473477 (2005). DOI: $10.1002 / \mathrm{adma} .200401416$

[12] Gao J., Zhang B., Zhang X., Xu B.: Magnetic-dipolarinteraction-induced self-assembly affords wires of hollow nanocrystals of cobalt selenide. Angewandte Chemie International Edition, 118, 1242-1245 (2006). DOI: 10.1002 /ange.200503486

[13] Li Q., Penner R. M.: Photoconductive cadmium sulfide hemicylindrical shell nanowire ensembles. Nano Letters, 5, 1720-1725 (2005).

DOI: $10.1021 / \mathrm{n} 1050994 \mathrm{x}$

[14] Fan H. J., Knez M., Scholz R., Nielsch K., Pippel E., Hesse D., Zacharias M., Gösele U.: Monocrystalline spinel nanotube fabrication based on the Kirkendall effect. Nature Materials, 5, 627-631 (2006).

DOI: $10.1038 /$ nmat1673

[15] Ng C. H. B., Tan H., Fan W. Y.: Formation of $\mathrm{Ag}_{2} \mathrm{Se}$ nanotubes and dendrite-like structures from UV irradiation of a $\mathrm{CSe}_{2} / \mathrm{Ag}$ colloidal solution. Langmuir, 22, 9712-9717 (2006).

DOI: $10.1021 / 1 \mathrm{a} 061253 \mathrm{u}$

[16] Cao S., Hu B., Liu H.: Fabrication of nano-porous structured polylactide (PLLA) fibers through electrospinning. Acta Polymerica Sinica, 10, 1193-1198 (2010).

DOI: 10.3724/SP.J.1105.2010.09391

[17] Yu Q-Z., Dai Z-W., Lan P.: Fabrication of high conductivity dual multi-porous poly (L-lactic acid)/polypyrrole composite micro/nanofiber film. Materials Science and Engineering B, 176, 913-920 (2011). DOI: $10.1016 /$ j.mseb.2011.05.017

[18] Koombhongse S., Liu W., Reneker D. H.: Flat polymer ribbons and other shapes by electrospinning. Journal of Polymer Science Part B: Polymer Physics, 39, 2598-2606 (2001). DOI: $10.1002 /$ polb.10015

[19] Yu Q-Z., Shi M-M., Deng M., Wang M., Chen H-Z.: Morphology and conductivity of polyaniline submicron fibers prepared by electrospinning. Materials Science and Engineering: B, 150, 70-76 (2008). DOI: $10.1016 /$ j.mseb.2008.02.008

[20] Xia X., Dong X. J., Wei Q. F., Cai Y. B., Lu K. Y.: Formation mechanism of porous hollow $\mathrm{SnO}_{2}$ nanofibers prepared by one-step electrospinning. Express Polymer Letters, 6, 169-176 (2012).

DOI: $10.3144 /$ expresspolymlett.2012.18 